TAMARIT, Josep. "Los límites de la justicia transicional penal:

la experiencia del caso español".

Polít. crim. Vol. 7, $\mathrm{N}^{\mathrm{o}} 13$ (Julio 2012), Art. 2, pp. 74 - 93.

[http://www.politicacriminal.cl/Vol_07/n_13/Vol7N13A2.pdf]

\title{
Los límites de la justicia transicional penal: la experiencia del caso español
}

\author{
Josep Tamarit Sumalla* \\ jmtamarit@dpub.udl.cat
}

\section{Resumen}

En la transición a la democracia en España, tras la larga dictadura franquista, no se exigieron responsabilidades penales por los crímenes cometidos bajo el régimen anterior. En la actualidad, los intentos por abrir una persecución penal de estos delitos han llegado demasiado tarde, dada la desaparición de los eventuales responsables de los hechos. En el artículo se analizan los obstáculos jurídicos a los que ha debido hacer frente la persecución penal, como la prohibición de retroactividad, la prescripción y los efectos de la Ley de amnistía de 1977, y se concluye con una reflexión sobre los límites intrínsecos a la justicia penal y la necesidad de explorar otras medidas propias de la justicia transicional.

\section{Palabras clave}

Justicia transicional, víctima, memoria histórica, franquismo, reparación, amnistía

\begin{abstract}
During the Spanish transition to democracy after Franco's dictatorship, no criminal proceedings were initiated in order to prosecute the crimes committed under the previous regime. Initiatives aimed to start a prosecution for such crimes came too late, since those who could be held responsible of the facts were dead. This article analyses the main legal issues concerned, such as prohibition of retroactivity, prescription and the effects of 1977 Amnesty Law. We conclude pointing out the limits of criminal justice and the need to explore other transitional justice measures.
\end{abstract}

\section{Key words}

Transitional justice, victim, historical memory, franquismo, reparations, amnesty

Índice: 1. Un caso insólito de justicia transicional. 2. Un proceso penal fallido. 3. Análisis de la problemática jurídico-penal. 3.1. Prohibición de retroactividad; 3.2. Prescripción; 3.3. Amnistía. 4. El caso de los niños perdidos y las adopciones ilegales. 5. Conclusiones.

\footnotetext{
* Catedrático de Derecho penal de la Universidad de Lleida y Director del Programa de Criminología de la Universitat Oberta de Catalunya.
} 
TAMARIT, Josep. "Los límites de la justicia transicional penal:

la experiencia del caso español".

\section{Un caso insólito de justicia transicional}

En la abundante literatura producida a escala internacional sobre justicia transicional, el caso español había despertado hasta tiempos recientes escasa atención. Ello puede resultar sorprendente, ya que presenta características muy diferenciadas respecto a otros procesos transicionales. A nivel interno la posibilidad de perseguir penalmente los crímenes del franquismo fue una cuestión que quedó totalmente al margen del debate político e incluso había atraído poco el interés de los medios de comunicación. La opinión generalizada era que la Ley de amnistía de 1977 había cerrado el paso a cualquier posibilidad de acudir a la vía penal para exigir responsabilidades a los autores de las violaciones más graves de derechos humanos ocurridas durante la dictadura franquista. La situación de absoluta impunidad respecto a estos crímenes era percibida por algunos con resignación, como el precio necesario que se pagó para conseguir la democracia, y para otros era incluso un hecho merecedor de elogios, como una de las características de una transición defendida como modélica. En cualquier caso, debemos tener en cuenta tres características del caso español que lo diferenciaban de otros procesos transicionales: a) las violaciones de derechos humanos más graves, cometidas con carácter masivo, habían tenido lugar en los primeros años del régimen (a finales de los años treinta y principios de los años cuarenta del sigo XX); b) el dictador había muerto, así como otros máximos responsables de esas atrocidades; c) a la muerte de Franco sus sucesores conservaban grandes resortes de poder y la sociedad, en la mayor parte de España, no cuestionaba de modo generalizado el franquismo. Todo ello tenía que ver con las características de la larga dictadura de Franco, implantada después de haber ganado una sangrienta guerra civil (1936-1939) con una durísima represión inicial concebida por el dictador como "inversión en terror" $\mathrm{y}$ de haber sido posteriormente acreditado su régimen en la escena internacional, lo cual le permitió mantener el poder hasta su muerte en noviembre de 1975.

La transición española ha sido señalada como ejemplo de transición basada en el olvido o como un supuesto de "tercera vía hacia la impunidad" entre la pura autoamnistía y el otorgamiento de actos de perdón. ${ }^{2} \mathrm{Si}$ nos atenemos a la distinción entre casos de victimización simétrica y asimétrica, ${ }^{3}$ en el caso español hay dos realidades que, aunque unidas entre sí, deben ser distinguidas: la guerra civil y la dictadura, caracterizada la primera por cierta simetría en los crímenes cometidos por los dos bandos enfrentados (si obviamos el hecho de que la represión en la retaguardia republicana no era atribuible directamente a las autoridades del régimen depuesto por Franco) y la segunda por una victimización básicamente asimétrica y vertical, protagonizada desde el poder contra la población. Pero ahí también es muy importante otra distinción, entre la primera etapa del régimen, en la que se cometieron las mayores atrocidades y violaciones de derechos humanos, y una segunda etapa en que se atenuó el furor represivo hasta el punto que algunos llegaron a utilizar en los últimos años de Franco la expresión "dictablanda", fase en

\footnotetext{
${ }^{1}$ Véase PRESTON, Paul, “E1 holocausto español”, Barcelona: Debate, 2010, pp. 536 y ss.

${ }^{2}$ Vid. HUYSE, Luc, "Justice after Transition: On the Choices Successor Elites Make in Dealing with the Past", en: KRITZ, Neil J. (Ed.), Transitional Justice: how emerging democracies reckon with former regimes, Washington D.C.: USIPP, 2004.

3 Esta distinción ha sido utilizada por UPRIMNY YEPES, Rodrigo, en DE GAMBOA TAPIAS, Camila (Ed.), Justicia transicional: teoría y praxis, Bogotá: Universidad del Rosario, 2006, pp. 30 y ss.
} 
Polít. crim. Vol. 7, № 13 (Julio 2012), Art. 2, pp. 74 - 93.

[http://www.politicacriminal.cl/Vol_07/n_13/Vol7N13A2.pdf]

que los atropellos de los derechos humanos ya no tenían un carácter "masivo" y apareció el fenómeno del terrorismo. Se manifiesta en ello el imperio del tiempo como agente de los procesos jurídicos y políticos. El transcurso del tiempo desde los actos que causan mayor conmoción social, como ha señalado Elster, ${ }^{4}$ reduce las demandas sociales de justicia. Volviendo a la primera distinción efectuada, el carácter "simétrico" de las victimizaciones sufridas favorecería en general soluciones de carácter "compensatorio", de modo que se renunciaría a exigir responsabilidades según una lógica propia de la "compensación de culpas", pero ello no sería así en los supuestos de "victimización vertical", aunque, claro está, no puede olvidarse que la condición para hacer efectiva cualquier forma de justicia es que se disponga efectivamente del poder de ejercerla y el poder democrático ha acusado en España una debilidad de origen, derivada del modelo de transición sin ruptura de la dictadura a la democracia.

Bajo estas premisas deben ser valoradas la ley de amnistía de 1976 y la más amplia de 1977, aprobada por el Parlamento surgido de las primeras elecciones democráticas de junio de 1977. La amnistía de los presos políticos, de todos aquellos que habían sufrido represión por su oposición al régimen franquista, era una de las principales reivindicaciones de los partidos democráticos. La Ley de amnistía fue aprobada con el voto favorable de más del $90 \%$ de los diputados, con el apoyo de los partidos políticos que representaban más claramente la oposición democrática al franquismo. La amnistía se extendía incluso a quienes habían cometido delitos de sangre si habían actuado por motivos políticos, lo que incluía a los miembros de ETA y otras organizaciones terroristas, y comprendía los "delitos $\mathrm{y}$ faltas que pudieran haber cometido las autoridades, funcionarios y agentes del orden público con motivo u ocasión de la investigación y persecución de los actos incluidos en esta Ley" y los "delitos cometidos por los funcionarios y los agentes del orden público contra el ejercicio de los derechos de las personas" (art 2 de la Ley de Amnistía de 6 de octubre de 1977). Se sellaba así un pacto, muy poco explicitado, por el que el régimen saliente accedía a la amnistía reclamada por las fuerzas democráticas a cambio de no tener que responder ni los dirigentes ni los lacayos de aquél por sus crímenes.

Para caracterizar la transición española suelen utilizarse expresiones como "olvido" o "reconciliación". La primera es muy adecuada y, así, se ha señalado con acierto que se trataba de una "transición amnésica". Sin embargo, la idea de reconciliación debe ser evitada, dado el uso altamente manipulador que se ha efectuado de la retórica de la reconciliación, a no ser que con la misma se quiera meramente expresar la antítesis que algunos han visto entre ésta y la justicia. Además, los requisitos de un proceso de reconciliación tal como ésta es entendida en la literatura sobre justicia transicional, a partir de las experiencias de las comisiones de la verdad en algunos países, ${ }^{6}$ no concurren en el caso español.

\footnotetext{
${ }^{4}$ Vid. ELSTER, Jon, Rendición de cuentas. El debate de la justicia transicional, Buenos Aires: Katz, 2004.

${ }^{5}$ Vid. REYES MATE, Manuel, Justicia de las víctimas. Terrorismo, memoria, reconciliación. Madrid: Anthropos, 2009.

${ }^{6}$ Vid. DALY, Erin; SARKIN, Jeremy, Reconciliation in divided Societies: Finding Common Ground, Estados Unidos: University of Pennsylvania Press, 2006; y HEYLEN, Ben; PARMENTIER, Stephan; WEITENKAMP, Elmar, "The Emergence of "Holistic Reconciliation": Lessons Learned from Victims and Offenders inside the South African Truth and Reconciliation Commission", International Perspectives in Victimology, v. 5 (2010), p. 7.
} 
TAMARIT, Josep. "Los límites de la justicia transicional penal:

la experiencia del caso español".

El modelo español de transición ha sido justamente definido por Gil como de "olvido con rehabilitación parcial", en la medida que se han satisfecho ciertas exigencias de reparación de las víctimas de la represión. ${ }^{7}$ Hay en un primer momento actos de rehabilitación de funcionarios represaliados y de reconocimiento a los herederos de fallecidos el derecho a percibir prestaciones debidas (Decreto de 5 de diciembre de 1975 y Decretos 27 de mayo y 2 de junio de 1977). Tras la aprobación de la Constitución de 1978 se inicia un proceso lento y gradual en el que el régimen democrático va adoptando decisiones de carácter reparador, que durante un tiempo responden a una lógica de equiparación, reconociendo a los perdedores de la guerra prestaciones de las que se beneficiaban hasta el momento sólo los vencedores, y tomando como referencia la guerra civil, como si no hubiera existido después una larga dictadura y no se hubiera salido aún totalmente de ella (así Leyes de 29 de marzo de 1982 y de 22 de octubre de 1984). No es hasta el año 1990 y a través de una Disposición Adicional a la Ley de Presupuestos del Estado (de 29 de junio de 1990) que se da el paso consistente en reconocer derechos de indemnización a favor de quienes sufrieron prisión durante 3 o más años y mediante la Ley de 18 de marzo de 2005 se aprueba una prestación económica a favor de los denominados "niños de la guerra". Respecto a la devolución de bienes incautados, el proceso de reparación ha sido también lento, gradual y limitado, alcanzando a los partidos y sindicatos pero no a los particulares. La condena explícita del régimen franquista y la calificación como ilegítimas de algunas de sus decisiones no se produce hasta la aprobación de la Ley 52/2007, por la que se reconocen y amplían derechos y se establecen medidas a favor de quienes padecieron persecución y violencia durante la guerra civil y la dictadura.

Esta última norma, conocida como "Ley de la memoria histórica" ha respondido a una voluntad de paliar las carencias del proceso de transición y ha recibido críticas de muy diverso signo, algunas de las cuales han destacado su oportunismo político o han entendido que llegaba demasiado tarde, mientras otras han denunciado que se queda corta en el reconocimiento de los derechos de las víctimas y en la reparación de las injusticias cometidas por el franquismo.

Los cuestionamientos de la impunidad de los crímenes del franquismo alcanzan una dimensión pública importante a finales del siglo XX. Un factor decisivo fue el proceso abierto por el Juez Baltasar Garzón contra Pinochet, como consecuencia de una acción presentada por diversas organizaciones civiles y víctimas de la dictadura chilena. En este caso la justicia penal española ejercía la jurisdicción universal, reconocida ampliamente por la legislación española (art 23 de la Ley Orgánica del Poder Judicial de 1985) y no estaba afectada por ninguna Ley de amnistía. Mucho más lejos llegó la justicia española en la aplicación del principio de justicia universal respecto a hechos de la dictadura argentina, con un proceso penal en el que el militar argentino Adolfo Scilingo fue condenado por la Audiencia Nacional en 2005 por delitos contra la humanidad. El Tribunal Supremo, en la sentencia de 1 de octubre de 2007, modificó el título condenatorio por entender que los

\footnotetext{
${ }^{7}$ La expresión es de GIL GIL, Alicia, La justicia de transición en España. De la amnistía a la memoria histórica, Barcelona: Atelier, 2009, p. 23. Vid. asimismo de la misma autora el informe referido a España en AMBOS, Kai; MALARINO, Ezequiel; ELSNER, Gisela (Eds.), Justicia de transición: Informes de América Latina, Alemania, Italia y España, Berlin: Konrad-Adenauer-Stiftung, 2009, disponible en: http://www.kas.de/wf/doc/kas 15990-1522-4-30.pdf?090629220310
} 
Polít. crim. Vol. 7, № 13 (Julio 2012), Art. 2, pp. 74 - 93.

[http://www.politicacriminal.cl/Vol_07/n_13/Vol7N13A2.pdf]

hechos no podían ser calificados como delitos contra la humanidad dado que eran anteriores a la tipificación de esta figura delictiva en el Código penal español, pero condenó al procesado por delitos de asesinato y detención ilegal.

A pesar de las justificaciones basadas en razones de estricta legalidad, el hecho de que España enjuiciara los crímenes de otras dictaduras sin haber sido capaz de enfrentar su propio pasado representó un argumento de mucho peso que afectó negativamente a la imagen del país y motivó una reacción interna de cuestionamiento del modelo transicional de impunidad. Todo ello se produce en un contexto de emergencia, a escala mundial, de la cultura de la memoria histórica y del creciente protagonismo de los derechos de las víctimas. Por otra parte, la Ley de memoria histórica no ha satisfecho algunas de las principales reivindicaciones de las asociaciones civiles, especialmente en lo tocante a las fosas comunes en las que fueron sepultadas las víctimas de las ejecuciones extrajudiciales masivas perpetradas por las tropas de Franco, respecto a las cuales la Ley se limita a prever subvenciones y dar facilidades para que sea la iniciativa privada la que efectúe labores de investigación, localización, identificación y dignificación. La frustración de la expectativa de que sea el Estado quien asuma esta labor ha estimulado el recurso a la justicia penal como medio de averiguación y establecimiento oficial de la verdad.

\section{Un proceso penal fallido}

El 16 de octubre de 2008 el Juez de Instrucción Baltasar Garzón inició una causa penal por delitos contra la humanidad, a partir de una querella presentada por diversas organizaciones sociales, en ejercicio de la "acción popular", que permite a los ciudadanos ejerces la acción penal aun sin tener condición de víctimas y al margen del Ministerio público. Según el auto del citado Juez, los delitos serían asesinatos y detenciones ilegales seguidas de desaparición, cometidos con carácter masivo entre el 17 de julio de 1936 y el 31 de diciembre de 1951, que habrían sido ordenados y dirigidos por los líderes de las fuerzas que se habían rebelado contra las instituciones legítimas. El auto considera que los delitos, que habían tenido lugar en todo el territorio del Estado, son conexos con un delito de rebelión, tipificado como delito contra los altos organismos del Estado y cuya competencia está legalmente atribuida a la Audiencia Nacional. En su auto, Garzón incluía un relato de los crímenes cometidos por las fuerzas encabezadas por Franco y otros generales, como Mola y Queipo de Llano, descritos como parte de un ataque planificado y sistemático contra los disidentes, con el propósito de eliminarlos. El Magistrado califica los hechos como delito contra la humanidad y para superar la prohibición de aplicación retroactiva de la norma penal, introducida en el CPE en 2003, invoca la "cláusula Martens", incluida en ed preámbulo de la Segunda Convención de La Haya relativa a las leyes de la guerra de 1899,

\footnotetext{
${ }^{8}$ Procedimiento Sumario núm. 53/2008 del Juzgado Central de Instrucción núm. 5.

Puede accederse a la documentación del caso a través del Portal iberoamericano de ciencias penales de la Universidad de Castilla La http://www.cienciaspenales.net/portal/page/portal/IDP/Dosier/Espa $\%$ F $1 \mathrm{a} \% 20$ proceso $\% 20 \mathrm{a} \% 201 \mathrm{los} \% 20 \mathrm{cr} \% \mathrm{E}$ Dmenes\%20de\%201a\%20Dictadura (consultado el 17 de agosto de 2011).

${ }^{9}$ Según dispone el Preámbulo, "hasta la elaboración de un código de leyes más completo, las altas partes contratantes consideran justo declarar que en los casos no incluidos en las regulaciones adoptadas por ellas, las poblaciones y los beligerantes permanecen bajo la protección y el imperio de los principios de derecho
} 
TAMARIT, Josep. "Los límites de la justicia transicional penal:

la experiencia del caso español".

así como el derecho de guerra vigente al tiempo en que ocurrieron los hechos investigados. Garzón afirma asimismo que el Pacto Internacional de derechos civiles y políticos (PIDCP) de 1966, en vigor en España desde 1977, exige a los Estados que investiguen los casos de desapariciones con riesgo para la vida o tortura (artículos 6 y 7). Para sortear el problema de la prescripción del delito el juez se basa en los siguientes argumentos: a) los crímenes contra la humanidad son imprescriptibles; b) si los hechos fueran considerados como delitos comunes, los casos en que no han sido hallados los cuerpos de las víctimas deberían ser calificados como "detención ilegal seguida de desaparición”, cuya naturaleza jurídica de delito permanente supone que la consumación se sigue produciendo mientras dura el estado antijurídico de desaparición y el cómputo de la prescripción no se iniciaría hasta que el mismo hubiera cesado.

En lo que atañe a la Ley de amnistía, el Magistrado asume la jurisprudencia de algunos tribunales internacionales, como la Corte Interamericana de Derechos Humanos, que han declarado la inadmisibilidad de las amnistías en los casos de graves violaciones de derechos humanos. Asimismo entiende que los delitos de desaparición forzada, en tanto que delitos permanentes, se han seguido cometiendo tras la aprobación de la Ley de amnistía e incluso después de la entrada en vigor de la Constitución en diciembre de 1978. La resolución culmina con un listado de los presuntos responsables de los delitos, encabezado por Franco y seguido por dirigentes del Ejército nacionalista vencedor de la guerra civil. Este ha sido el elemento más criticado de la resolución de Garzón, dado que se trata de personas cuya muerte constituía un hecho notorio, por lo cual se ha reprochado al Magistrado un uso del proceso penal como instrumento al servicio de fines ajenos a los que le son propios, siguiendo el precedente de los "juicios de la verdad" en Argentina, criticados también en su día por ser meros instrumentos de investigación vacíos de contenido punitivo real. En todo caso, poco después de abierto el procedimiento, mediante auto de 18 de noviembre de 2008, dejando constancia del fallecimiento de los posibles imputados, Garzón se inhibió, poniendo fin al mismo.

El 2 de febrero de 2009 el plenario de la Audiencia Nacional decidió sobreseer el procedimiento, acogiendo el recurso que el Ministerio público había presentado contra el primer auto de Garzón. La Sala estableció que ninguno de los delitos entraba dentro de la competencia de la Audiencia Nacional y que serían competentes los tribunales territoriales de los lugares donde los diversos delitos hubieran sido cometidos. En cuanto a la descripción legal de los hechos, la Sala rechazó la posibilidad de enjuiciarlos como delitos contra la humanidad al ser éste un tipo delictivo inexistente en el momento de su comisión ni en la legislación española ni siquiera en el Derecho internacional. La "cláusula Martens" no podía en ningún caso servir como referencia en tanto que ley previa dado que no incluía una descripción de delitos y el derecho de guerra no sería aplicable más que a conflictos armados internacionales, no siendo éste el caso de la guerra española. Acogiendo los

internacional, tal como resultan de los usos establecidos por la naciones civilizadas, las leyes de la humanidad y las exigencias de la conciencia pública".

${ }^{10}$ Similares obligaciones derivan de la Convención europea de derechos humanos de 1950 (art 2) y de la Convención de las Naciones Unidas sobre desapariciones forzosas de 2006 (art 12).

${ }^{11}$ Vid. PASTOR, Daniel, El poder penal internacional. Una aproximación jurídica crítica a los fundamentos del Estatuto de Roma. Barcelona: Atelier, 2006. 
Polít. crim. Vol. 7, No 13 (Julio 2012), Art. 2, pp. 74 - 93. [http://www.politicacriminal.cl/Vol_07/n_13/Vol7N13A2.pdf]

argumentos del recurso del Fiscal, la Sala censura la pretensión de aplicación retroactiva de la norma que declara la imprescriptibilidad de los delitos contra la humanidad, dado que una tal norma no existía en el momento de la comisión de los hechos ni en el Derecho español ni en el Derecho internacional consuetudinario. Tampoco los hechos podrían ser considerados como detención ilegal seguida de desaparición puesto que esta modalidad delictiva no fue introducida en el Derecho español hasta la aprobación del Código penal de 1944 y porque en todo caso se trataría de muertes y no de desapariciones, por ser un hecho notorio que las detenciones habían tenido como consecuencia la muerte de las víctimas. Finalmente, la Sala afirma la plena aplicabilidad de la Ley de amnistía, que no se limitaba a los delitos políticos y se extendía a los delitos cometidos por las autoridades y sus agentes contra los derechos de las personas. Por otra parte, la norma internacional que prohíbe las amnistías en los casos de violaciones graves de derechos humanos en ningún caso se podría considerar existente al tiempo de la aprobación de la Ley de 1977 y por lo tanto no cabe extinguir retroactivamente los efectos ya producidos por la indicada Ley.

La decisión fue adoptada por 12 votos y se emitieron tres votos particulares favorables a confirmar el auto del Juez instructor. La decisión del pleno de la Audiencia Nacional fue la resolución definitiva, tras la cual las organizaciones promotoras de la persecución penal acudieron a diversos jueces territoriales, alguno de los cuales aceptó abrir una investigación ordenando la apertura de fosas. Posteriormente el Juez Garzón ha sido acusado de prevariación por haber dictado a sabiendas una resolución injusta y el Tribunal Supremo ha abierto un proceso penal contra el Magistrado, a instancias de La Falange, una organización de extrema derecha heredera directa de uno de los grupos paramilitares que apoyaron el levantamiento contra la República y participaron en los crímenes que Garzón trataba de investigar, y dos presuntas organizaciones sindicales, "Manos Limpias" y "Unión nacional de trabajadores". El proceso contra Garzón ha recibido fuertes críticas fuera y dentro de España y ha concluido con la sentencia de la Sala de lo Penal del Tribunal Supremo de 27 de febrero de 2012, que le absuelve del delito de prevaricación.

Antes de exponer las razones en que se funda la absolución, la fundamentación jurídica de la sentencia contiene un detallado análisis de la actuación del Magistrado, en la que se afirma que su decisión de iniciar el proceso penal se basó en una aplicación errónea del Derecho. En la sentencia se exponen los motivos por los que el juez acusado de prevaricación incurrió en error, pero la Sala considera que el error fue corregido por vía jurisdiccional a través del sistema de recursos y que la decisión judicial errónea no contenía el "plus" de antijuridicidad necesario para la concurrencia del delito de prevaricación, puesto que la actuación del juez "fue dirigida a disponer la tutela que le reclamaban quienes eran víctimas de unos delitos hoy día calificables como delitos contra la humanidad, que se encontraban en una situación de objetiva desigualdad respecto a otras víctimas de hechos sustancialmente similares y coetáneos en el tiempo de la guerra civil". La sentencia reconoce que la reparación de las consecuencias de la guerra y la posguerra ha sido parcial, pues "no han concluido las actuaciones concretas en orden a la localización y recuperación de os cadáveres parø su homenaje y procurar la efectiva reconciliación que la Ley de Amnistía persiguió". Atendiendo a tal propósito y a la existencia de tal razonable petición

\footnotetext{
${ }^{12}$ STS de 27 de febrero de 2012, FJ 4.
} 
TAMARIT, Josep. "Los límites de la justicia transicional penal:

la experiencia del caso español".

de justicia por parte de las víctimas y a que la interpretación jurídica en que se basaba Garzón, que no se deja de calificar de errónea, ha sido también sostenida por otros juristas y operadores jurídicos, la decisión del Magistrado no es calificada como prevaricadora. En cualquier caso, el Tribunal Supremo no duda en entrar a fondo en los argumentos de los partidarios de la perseguibilidad de los crímenes del franquismo y reafirma los principales obstáculos que la impiden: los hechos no podían ser calificados como delito contra la humanidad en el momento de su comisión, están prescritos y cubiertos por la Ley de amnistía. Y en la defensa de estos postulados la sentencia no acude tan sólo a argumentos jurídicos ya conocidos, como la prohibición de aplicación retroactiva, la sujeción de los jueces penales a la ley penal interna vigente al momento del hecho y la inviabilidad de valorar hechos remotos a la luz de la actual cultura jurídica sobre los derechos humanos o la inaplicabilidad de la jurisprudencia de la Corte interamericana de derechos humanos. La Sala afirma que no tienen cabida en el sistema procesal español los denominados juicios de la verdad, que pretenden una indagación judicial de unos hechos sin intervención del imputado y sin posibilidad de conducir a la imposición de una pena. Además rechaza que el derecho a conocer la verdad histórica pueda invocarse y ser satisfecho plenamente en el proceso penal, dado que el método de la investigación judicial no el propio del historiador. Asimismo el Tribunal se adentra en valoraciones sobre el proceso de transición y asume el relato oficial sobre su "carácter modélico" (sic), señalando, respecto a la Ley de amnistía, que la misma fue "voluntad del pueblo español", por lo que ningún juez o Tribunal puede cuestionar su legitimidad: "Se trata de una ley vigente, cuya eventual derogación correspondería, en exclusiva, al Parlamento".

Vamos a analizar a continuación los tres aspectos en los que se centra la controversia respecto a la viabilidad, desde el punto de vista jurídico-penal, de un proceso penal por los delitos cometidos con carácter masivo por Franco y otros dirigentes del régimen autocrático. Estos aspectos son la prohibición de aplicación retroactiva de la ley penal, la prescripción del delito y la amnistía.

\section{Análisis de la problemática jurídico-penal}

\subsection{Prohibición de retroactividad}

La primera cuestión planteada sería la determinación de la ley penal aplicable al tiempo de comisión de los delitos, dada la prohibición constitucional (art $9 \mathrm{CE}$ ) y legal (art $1 \mathrm{CPE}$ ) de la aplicación retroactiva de normas penales. Las ejecuciones extrajudiciales y desapariciones de personas, practicadas con carácter masivo y con la finalidad de eliminar y aterrorizar a quienes habían ejercido cargos durante la República, pertenecían a organizaciones que permanecieron fieles a la legalidad republicana o se habían opuesto al levantamiento militar, constituirían según la ley penal española hoy vigente un delito contra la humanidad. Este tipo delictivo fue introducido en el art 607 bis CPE el 25 de noviembre de 2003, que entró en vigor en 2004. Para evitar que una eventual condena infringiese la prohibición de aplicación retroactiva son imaginables tres vías, si tenemos en cuenta los precedentes existentes en otros países e incluso en España. La primera sería acudir a

\footnotetext{
${ }^{13}$ Vid. STS de 27 de febrero de 2012, FJ 3.
} 
Polít. crim. Vol. 7, № 13 (Julio 2012), Art. 2, pp. 74 - 93.

[http://www.politicacriminal.cl/Vol_07/n_13/Vol7N13A2.pdf]

razonamientos inspirados en el Derecho natural, como la invocación de la "cláusula Radbruch", que supondría aceptar la existencia de una excepción a la prohibición de retroactividad respecto a aquellos hechos de los que, con independencia de lo plasmado en el Derecho escrito en el momento de su comisión, nadie hubiera podido razonablemente dudar de su carácter injusto y atroz, de modo que no quedaría afectada la previsibilidad de la sanción por parte de sus autores (prior notice). A favor del recurso a argumentos supralegales se ha señalado que de otro modo estaría en manos de los dictadores en ejercicio de su poder absoluto dictar normas que les garantizaran no tener que responder nunca por sus fechorías, por lo que las nuevas autoridades democráticas no estarían vinculadas por las normas dictadas bajo una tiranía con la finalidad de impedir la persecución de hechos cuyo carácter delictivo estuviera fuera de toda duda a la luz del sentimiento natural del Derecho. Frente a tal forma de argumentación, además de las reticencias que con carácter general acostumbra a despertar la apelación a criterios de Derecho natural (elitismo epistemológico, dudas sobre su reconocimiento...), habría que tener en cuenta el problema de la determinación de la pena aplicable en un sistema en el que se rige de modo estricto por la legalidad de las penas que los jueces pueden aplicar a los responsables de un delito (garantía penal).

La segunda vía es el recurso al Derecho internacional, por la cual han transcurrido en general en España las alegaciones de los partidarios de la persecución, quienes advierten que la figura del delito contra la humanidad existía ya en el Derecho internacional consuetudinario antes de su recepción y tipificación en el Derecho interno. Sin embargo, la cláusula Martens es un asidero insuficiente en el que basar la existencia de una ley penal previa, dado que no tiene tal naturaleza. Gil ha afirmado que los crímenes cometidos durante la guerra civil y los primeros años del franquismo en ningún caso podrían ser considerados como delitos internacionales dado que la definición de genocidio y de delitos contra la humanidad fue elaborada posteriormente, así como el reconocimiento de la responsabilidad individual por conflictos internos, de modo que en ningún caso habría una norma internacional a la que acogerse hasta el 29 de julio de 1950, cuando la Comisión de Derecho internacional elaboró los principios de Nüremberg en cumplimiento del mandato de la Asamblea General de Naciones Unidas de 11 de diciembre de $1946 .{ }^{14}$ Incluso no sería hasta 1954 la concepción de esta figura como delito que podría ser cometido también fuera del contexto de un conflicto armado. En todo caso, según esta opinión doctrinal, no sería ésta la única razón que impediría la aplicación directa de las normas de Derecho internacional. El incumplimiento de las obligaciones internacionales de incriminación generaría responsabilidad internacional del Estado, pero los jueces internos no pueden aplicar más que las leyes penales nacionales en vigor en el momento de la comisión de los hechos. El Derecho internacional consuetudinario no contiene normas penales completas, por lo que los jueces nacionales no podrían aplicarlas directamente por falta de contenidos esenciales desde el prisma del principio de legalidad, como la definición taxativa de las conductas punibles y la pena aplicable.

Esta posición ha sido cuestionada por un sector de la doctrina internacionalista española, que ha sostenido la aplicabilidad de las normas de ius cogens que son obligatorias per se en

${ }^{14}$ GIL GIL, La justicia de transición, cit. nota $n^{\circ}$ 7, pp. 114-115. 
TAMARIT, Josep. "Los límites de la justicia transicional penal: la experiencia del caso español".

la medida que la comunidad internacional se ha mostrado interesada en que sean perseguidos y sancionados penalmente comportamientos que atentan contra los valores comunes de la humanidad. ${ }^{15}$ De acuerdo con esta opinión, el CPE ha incorporado tardíamente una categoría pre-existente en el Derecho internacional consuetudinario y el principio de legalidad no puede ser entendido tan sólo en clave interna, tal como refleja el art 15 del PIDCP de 1966 (ratificado por España el 27 de abril de 1977), según el cual "nadie puede ser declarado culpable de un hecho delictivo por un acto que no constituya delito según el Derecho nacional o internacional al tiempo en que fue cometido".

En tercer lugar, ante los insalvables escollos que, al menos según la opinión doctrinal dominante, impiden calificar retroactivamente los hechos como delitos contra la humanidad, se ha planteado la posibilidad de acudir a los tipos delictivos de asesinato y detención ilegal, según el Código penal de 1932 vigente al momento de los hechos. Esta ha sido, como se ha visto, la vía seguida por el Tribunal Supremo en el caso Scilingo, modificando la primera sentencia que había condenado por delitos contra la humanidad, pero esta vía no ha resultado atractiva para los promotores de la persecución de los crímenes del franquismo, porque han tenido que luchar contra el efecto de la prescripción y han intentado acogerse al carácter imprescriptible de los delitos contra la humanidad. Ciertamente resulta enormemente dificultoso pretender calificar los hechos como delitos comunes y aplicar las normas sobre imprescriptibilidad de los delitos contra la humanidad, pues, además de que ello supone enfrentarse una vez más a un problema de retroactividad (en este caso de la norma que declara el carácter imprescriptible del referido delito), representaría el intento de componer una "ley a la medida" con elementos de leyes distintas, con violación del principio de legalidad. De todos modos la posibilidad de condenar por asesinato no plantearía problemas desde el punto de vista de la prohibición de retroactividad y no habría nada que oponer a que los hechos fueran valorados y enjuiciados según los principios propios de un Derecho democrático y no según los de un régimen autocrático, siguiendo el criterio establecido por la Corte europea de derechos humanos en el caso de los tiradores del muro de Berlin (sentencia de 22 de marzo de 2001 en el caso de Streletz, Kessler y Krenz contra Alemania), aunque quedaría por analizar el problema de la prescripción y de la ley de amnistía, según veremos posteriormente.

En los supuestos en los que no ha podido establecerse la muerte de quienes fueron detenidos arbitrariamente y que por lo tanto cabe considerar como desaparecidos, la calificación de los supuestos de detención ilegal seguida de desaparición forzada tropieza con una serie de escollos, pues el actual tipo delictivo de detención ilegal seguida de desaparición forzada (art $163 \mathrm{CPE}$ ) no existía en el CP de 1932 y el antecesor de este tipo penal fue introducido en art 483 del CP de 1944, que fue interpretado como un delito de sospecha de asesinato. Ello permitiría perseguir sólo los hechos cometidos tras la entrada en vigor del Código de 1944, interpretando, según la doctrina anteriormente señalada de la $\mathrm{CEDH}$, a la luz del desarrollo del concepto de desaparición forzada. Los hechos anteriores a esa fecha en que no pudiera declararse la muerte sólo podrían ser calificados como detención ilegal.

\footnotetext{
${ }^{15}$ Así, PIGRAU SOLÉ, Antoni, "La jurisdicción universal y su aplicación en España”, Barcelona: RxDH, 2009, pp. 130-131. También en apoyo de las tesis favorables a la persecución CAPELLÀ ROIG, Margalida, "Los crímenes contra la humanidad en el caso Scilingo", REEI N 10 (2005).
} 
Polít. crim. Vol. 7, No 13 (Julio 2012), Art. 2, pp. 74 - 93.

[http://www.politicacriminal.cl/Vol_07/n_13/Vol7N13A2.pdf]

Está claro que por esta vía no podría asegurarse la persecución de las torturas, cometidas durante toda la dictadura, ya que este delito no estaba tipificado en el Código penal vigente $\mathrm{y}$ en todo caso las penas que hubieran podido imponerse, si los hechos no iban acompañados de lesiones, homicidio o detención ilegal, eran ridículas.

\subsection{Prescripción}

Según la opinión doctrinal dominante, las normas sobre prescripción del delito tienen un carácter de norma sustantiva que no permite su aplicación retroactiva. En todo caso, un examen más profundo debería considerar el fundamento no unívoco de esta disposición y tener en cuenta la excepcionalidad que supone la necesidad de enjuiciamiento de delitos cometidos desde el poder en una dictadura, durante la cual no existen las condiciones fácticas para ejercer la acción penal por tales delitos. El Tribunal Supremo en el orden civil ha establecido que el cómputo del tiempo de prescripción para la reclamación de propiedades ilegalmente apropiadas durante la guerra civil o los primeros años del franquismo debe iniciarse desde la fecha de la entrada en vigor de la Constitución ( 29 de diciembre de 1978). El mismo criterio debería haberse adoptado en el orden penal, como se hizo en Alemania en el enjuiciamiento de los tiradores del muro de Berlín, sin que pueda considerarse que con ello se produce vulneración del principio de legalidad. ${ }^{16}$ Este criterio hubiera permitido abrir procesos penales en los primeros años de régimen democrático, pero no ahora, dado que han transcurrido ya más de los veinte años que el CPE 1944 fijaba como tiempo de prescripción del asesinato.

Distinto sería el caso de las detenciones ilegales seguidas de desaparición, en que al ser un delito de consumación permanente el cómputo del plazo de prescripción se inicia en el momento en que finaliza el estado antijurídico de privación de libertad. Pero la valoración del problema de las desapariciones forzadas resulta extremadamente compleja. En los supuestos de detención ilegal o secuestro el estado antijurídico permanece vivo durante todo el tiempo en que se prolonga la privación de libertad bajo el control del autor, pues resulta fácil aceptar la idea de que se sigue consumando el delito en la medida que sigue ejerciendo el dominio del hecho objetiva y subjetivamente, con un dolo simultáneo al hecho que se sigue consumando. Pero la situación es distinta en los casos de desaparición forzada y para resolver el problema es necesario distinguir dos dimensiones. En primer lugar, la desaparición es esencialmente una "situación jurídica" caracterizada por la incertidumbre respecto a al destino de quien ha sido ilegalmente privado de libertad, de modo que su situación es la "desaparecido" porque no existe certeza respecto a si está vivo o muerto (incerteza que podría hipotéticamente alcanzar, en caso de estar vivo, a si está libre o en poder de sus secuestradores). Sin embargo, la desaparición entraña también una dimensión fáctica, consistente en la victimización indirecta producida sobre las personas cercanas al desaparecido, victimización de carácter psíquico producida por la imposibilidad de cerrar la herida y elaborar el duelo. Así se reconoce en el art 15 de la Convención internacional para la protección de todas las personas contra la desaparición forzada de 6 de febrero de 2007, según el cual "se entenderá por "víctima" la persona desaparecida y toda persona física que haya sufrido un perjuicio directo como consecuencia de una desaparición forzada" Por otra

\footnotetext{
${ }^{16}$ GIL GIL, La justicia de transición, cit. nota $\mathrm{n}^{\mathrm{o}} 7$, sin embargo considera que al no ser un supuesto de interrupción expresamente previsto por la ley se incurriría en una vulneración del referido principio.
} 
TAMARIT, Josep. "Los límites de la justicia transicional penal:

la experiencia del caso español".

parte, no puede olvidarse que el carácter permanente se predica del resultado, no de la acción, y en los delitos de resultado, que admiten el fraccionamiento espacio-temporal entre resultado y acción, existe la tesis que acepta que el inicio del plazo de prescripción se inicia en el momento de la consumación, incluso en los supuestos de daños producidos a largo plazo.

La pasividad institucional ante la situación de las personas que fueron sacadas de sus casas y fueron probablemente asesinadas y sus restos depositados en fosas comunes resulta un escándalo jurídico y ético. Durante muchos años, los gobiernos democráticos no han emprendido acciones para identificar los restos, conocer su paradero y establecer su situación jurídica. El intento de cerrar el asunto desde la Fiscalía alegando que la muerte de esas personas, nunca investigada ni oficialmente reconocida, es un "hecho notorio", muestra una enorme fragilidad. Puede parecer artificioso e irreal seguir sosteniendo en la actualidad la tesis de una consumación perpetua, pues hay indicios de que en su mayor parte los desaparecidos estaban muertos desde el primer momento y además, pese a su dimensión fáctica, la condición de desaparecido no es inmune al paso del tiempo, de modo que, como ha reconocido el Tribunal europeo de derechos humanos, como mayor sea el tiempo transcurrido mayor es la probabilidad de que la persona esté muerta. No obstante, por muy artificioso que pueda parecer, la situación jurídica de muchas de las víctimas de la feroz represión franquista es la de desaparecidos, hasta el punto de que no se había producido la declaración oficial de fallecimiento, como se ha hecho patente mediante la aprobación de la Disposición adicional $8^{\text {a }}$ de la Ley de registro civil de 21 de julio de 2011 , promovida por las asociaciones de recuperación de la memoria histórica, en virtud de la cual resulta ahora posible inscribir el fallecimiento sin necesidad de resolución judicial, con lo que los desaparecidos pueden pasar, pese a la inexistencia de prueba judicial de la muerte o proceso judicial de declaración de fallecimiento, a ser reconocidos como fallecidos y no como ausentes. Por lo tanto resulta plenamente razonable la aplicación de lo dispuesto en el art $132 \mathrm{CPE}$ respecto a que el cómputo del plazo de prescripción se hará desde el momento en que cesa la situación antijurídica. La Convención internacional de 2007 confirma este criterio en su art 5 al prever que, sin perjuicio de la aplicación del régimen de imprescriptibilidad de los delitos contra la humanidad, "cada Estado Parte que aplique un régimen de prescripción a la desaparición forzada tomará las medidas necesarias para que el plazo de prescripción de la acción penal: $a$ ) Sea prolongado y proporcionado a la extrema gravedad de este delito; $b$ ) Se cuente a partir del momento en que cesa la desaparición forzada, habida cuenta del carácter continuo de este delito.". No habiéndose establecido oficialmente el destino de estas personas ni existiendo norma alguna que fije un límite temporal, hay que concluir que el único límite a la perseguibilidad es, al menos de entrada, el que supone la posibilidad de enjuiciamiento de responsables vivos de los hechos y la disponibilidad de material probatorio. Sólo después de un proceso en que se pudiera hacer constar como probada la fecha del fallecimiento de la víctima podría declararse extinguida la responsabilidad penal por prescripción del delito, pero la situación inicial de desaparecido permitiría y exigiría, de entrada, la apertura del proceso. 
Polit. crim. Vol. 7, № 13 (Julio 2012), Art. 2, pp. 74 - 93.

[http://www.politicacriminal.cl/Vol_07/n_13/Vol7N13A2.pdf]

\subsection{Amnistía}

Hoy en día existe un amplio consenso respecto al carácter ilegítimo de las "autoamnistías" y también de las amnistías absolutas que alcancen, de modo incondicionado, a las violaciones de derechos humanos $\mathrm{y}$, sin cumplir con unas exigencias de justicia $\mathrm{y}$ reparación, lleven a la pura impunidad. La garantía de no impunidad y los derechos de las víctimas a la verdad, la justicia y la reparación son ya hoy principios jurídicos asentados en el plano internacional. ${ }^{17}$ Pero la discusión está en si podía considerarse ilegítima la referida Ley cuando fue aprobada y, en caso afirmativo, si algún órgano interno podría declararla nula. Niega esta posibilidad Gil, ${ }^{18}$ advirtiendo que no bastaría, para poder acometer hoy el juzgamiento de delitos cometidos por los servidores del franquismo, con la consideración de la ley de amnistía como meramente "derogada" por la posterior evolución del derecho internacional, dado que habría ya agotado sus efectos con la extinción, en el momento de su entrada en vigor, de las posibles responsabilidades penales. Por esta razón en Argentina hubo que considerar las leyes de punto final y de obediencia debida como "leyes de facto" para poder ser después declaradas nulas y carentes de efectos jurídicos. ${ }^{19}$

Parece razonable el criterio según el cual la Ley de amnistía no puede ser declarada nula por ilegitimidad sobrevenida, lo cual implicaría la aplicación retroactiva de una norma de derecho internacional consuetudinario cuya existencia en el momento en que la Ley fue dictada era dudosa. Por otra parte, buena parte de la doctrina destaca el carácter excepcional de la amnistía, que sólo estaría justificada por razones extraordinarias de necesidad y en la medida que con la misma se consigan los objetivos de pacificación y reconciliación y no se desatiendan las exigencias de justicia y reparación a favor de las víctimas. ${ }^{20}$ Ante ello queda la posibilidad de promover una interpretación restrictiva de la Ley, que atienda al contexto en que la misma fue aprobada, después de haberse ratificado por parte de España el Pacto internacional de derechos civiles y políticos de 1966 (BOE 30 de abril de 1977). La aprobación de la amnistía meses después de la referida ratificación no es algo que el jurista pueda meramente explicar como políticamente contradictorio sino como una circunstancia decisiva que enmarca el contexto en que debe efectuarse la interpretación de la norma, dado que el Pacto impone el deber de los Estados de investigar las violaciones de derechos humanos y de ofrecer recursos a las víctimas. Antes de alcanzar conclusiones precipitadas, conviene recordar que el Pacto (art 2, 3 y 15-2) no establece propiamente una obligación de los Estados de perseguir penalmente los hechos y, además, una interpretación restrictiva debe partir de ciertas cautelas, dados los términos en que se formulan los

\footnotetext{
${ }^{17}$ Un destacado sector doctrinal distingue entre estas amnistías y las amnistías condicionadas, que serían jurídicamente aceptables en la medida que resulten satisfechos los derechos de las víctimas, entendiendo que éstos no pueden identificarse con un derecho a la justicia penal. Este es el "enfoque flexible" que defiende, por ejemplo, Ambos, que remite la cuestión a un complejo proceso de ponderación de los intereses en conflicto que tenga en cuenta las circunstancias de cada proceso transicional. Vid. AMBOS, en AMBOS/MALARINO/ELSNER, Justicia de transición, cit. nota n 7, pp. 24 y 71 y ss.

${ }^{18}$ Vid. GIL GIL, La justicia de transición, cit. nota ${ }^{\circ} 7$.

19 Vid. NINO, Carlos Santiago, "The duty to punish past abuses of human rights put into context: the case of Argentina", en: KRITZ, Transitional Justice, cit. nota ${ }^{\circ}$ 2, pp. 434-436.

20 Vid. recientemente en este sentido LASCURAIN, Juan Antonio, "Los límites de la amnistía", Doctrina penal $\mathrm{N}^{\mathrm{o}} 28$ (2011), pp. 95 y ss., aunque sin referirse a los intereses de las víctimas establecidos en las declaraciones internacionales anteriormente citadas.
} 
TAMARIT, Josep. "Los límites de la justicia transicional penal:

la experiencia del caso español".

supuestos por los que se concede la amnistía, que impiden considerar excluidos de la amnistía todos los delitos cometidos desde el poder, ya que la propia Ley cuida de precisar que en todo caso debe considerarse amnistiado el delito de rebelión, que no puede tener otros destinatarios que aquellos que protagonizaron la sublevación militar contra la República. Además, se incluyen expresamente los delitos que hubieran podido cometer las autoridades, funcionarios y agentes con motivo u ocasión de la investigación y persecución de los actos, lo cual impide excluir de la amnistía supuestos de tortura y delitos relacionados, máxime si además tenemos en cuenta que la Convención sobre la tortura que obliga a los Estados a su persecución es de 1984.

Sea como fuere, los crímenes más graves perpetrados u ordenados por las autoridades contra la población civil deberían ser considerados fuera de la Ley de amnistía. Al no estar incluidos ni en el preámbulo ni en el texto de la Ley ni en el de los Decretos que la precedían puede entenderse que están implícitamente excluidos. El concepto de delito político es un elemento clave en la aplicación de la Ley de amnistía. Garcés ha argumentado que los jueces deben interpretar la ley a la hora de valorar si se encuentran ante un delito político. ${ }^{21}$ Cabe entender que los delitos contra la humanidad no pertenecen a la esfera de delitos políticos, con independencia de que esta tipología conceptual existiera al tiempo de comisión, pues los hechos en sí, sea cual fuera su categorización legal, iban más allá de la noción de delito político. La amnistía por delitos políticos es una manifestación de una actitud liberal que preconiza un trato favorable a esta clase de delitos en determinados contextos, como es el propio de los procesos de transición. Su razón de ser político-criminal es la de dispensar un trato indulgente respecto a quienes hubieran actuado ilegalmente por motivos nobles o bien en un contexto de conflicto civil y enfrentamiento recíproco o en un status quo en el que la participación política por medios pacíficos no era posible, como sucede en el contexto de un régimen autocrático. Extender la amnistía hasta los más graves crímenes de abuso de poder cometidos unilateralmente contra la población estaría fuera del contexto en que se aprobó la Ley de amnistía, que fue una respuesta a las demandas ciudadanas de liberación de los presos políticos (según el lema "libertad y amnistía" que en ese tiempo se gritaba en las calles) y con el propósito de superar las limitaciones de los decretos de 1976 y marzo de 1977. Durante la tramitación parlamentaria, la proposición de ley preparada inicialmente por los partidos que no habían tenido vinculación con el franquismo, fue modificada y su versión final incluyó, entre otros, la rebelión, los “delitos y faltas que pudieran haber cometido las autoridades y empleados públicos en la investigación y persecución de los actos incluidos en la ley" y "los delitos cometidos por funcionarios en violación de los derechos de las personas". Estos supuestos fueron añadidos a los delitos puramente políticos y fueron asumidos por los promotores de la amnistía como concesión para facilitar el consenso y de acuerdo con una lógica compensatoria.

Un examen de la discusión parlamentaria de la proposición de ley de amnistía refleja que la misma se tramitó con gran celeridad y escaso debate. En las intervenciones de los portavoces prácticamente no hubo referencias a los delitos cometidos por los servidores del régimen franquista $\mathrm{y}$, entre los que daban apoyo al texto propuesto, en todo caso se destacaba en tono crítico una excesiva limitación del alcance de la amnistía en aspectos

\footnotetext{
${ }^{21}$ Vid. GARCÉS, J., "La Ley Española 46/1977 de Amnistía, más citada que leída, no tiene por objeto actos de naturaleza genocida y lesa humanidad", en: http://www.rebellion.org/docs/105976.pdf
} 
Polít. crim. Vol. 7, № 13 (Julio 2012), Art. 2, pp. 74 - 93.

[http://www.politicacriminal.cl/Vol_07/n_13/Vol7N13A2.pdf]

menores, como, por ejemplo, en las penas accesorias, o se pedían indultos para ciertos delitos no políticos. Los portavoces insistían en las ideas de reconciliación y de olvidar el pasado y mirar hacia el futuro. Marcelino Camacho, representante del Grupo comunista, afirmó que "nos hemos matado unos a otros" y ahora "hemos enterrado nuestros muertos y nuestros rencores del pasado", defendiendo con entusiasmo una amnistía "para todos". E1 socialista Txiki Benegas aseguraba que "la sola idea de poder conquistar de nuevo la libertad perdida acalla y hace olvidar los sufrimientos soportados" y Xavier Arzallus, en representación del Grupo vasco-catalán, apelaba al "mutuo olvido", dado que "hechos de sangre ha habido por ambas partes". 22 Finalmente, la ley se aprobó con 296 votos a favor, 2 en contra y 18 abstenciones, del partido derechista Alianza Popular y algunos partidos de izquierda integrados en el Grupo mixto.

En cualquier caso, los diputados apenas distinguieron entre la guerra civil y el franquismo y obviaron toda alusión expresa a los crímenes cometidos de forma masiva una vez terminada la guerra. Por lo demás, poco puede aportar una especulación sobre la voluntad legislativa en puros términos de una interpretación subjetiva. De acuerdo con una interpretación objetiva y con criterios teleológico-sistemáticos, no parece viable equiparar los casos de violaciones masivas de derechos humanos con los delitos políticos que desde el principio habían sido el objetivo de la iniciativa legislativa. En términos de hermenéutica jurídica, la interpretación sólo puede hacerse en el contexto normativo trazado por la Declaración de Derechos humanos (1948) y desarrollada por la Convención europea de derechos humanos (1950) y el PIDCP, ambos ratificados por España en 1977. En este contexto tendría poco sentido entender que el mismo Parlamento constituido tras las elecciones de 15 de junio de 1977 extendiera la amnistía a delitos de genocidio y contra la humanidad sin referirse explícitamente a los mismos. ${ }^{23}$ En el contexto de los valores vigentes en el momento en que la Ley fue adoptada, cuando el primer Parlamento elegido democráticamente tras la dictadura trataba de erigir un nuevo régimen fundado en el respeto al Derecho y a los derechos humanos, el genocidio y los crímenes de lesa humanidad no puede interpretarse que estuvieran incluidos sin más entre los "delitos de intencionalidad política". La definición de los delitos contra la humanidad se produce posteriormente, en el Estatuto de Roma (1998) y en el CPE (2003), sobre la base de la idea que se había ido forjando ya en el Derecho internacional, lo cual hace visible que la conceptualización de esta clase de delito representa una contradicción con todo intento de concebirlo como un delito político en el sentido propio de la tradición liberal que acepta la oportunidad de un trato benévolo para estos crímenes.

Este criterio permitiría perseguir los delitos no prescritos, tal como sucedería, según hemos señalado anteriormente, con las detenciones ilegales seguidas de desaparición forzada. La persecución sería teóricamente posible porque se trataría de delitos no cubiertos por la Ley de amnistía, no por considerar que los mismos se seguirían cometiendo después de la aprobación de la citada Ley, pues ésta adopta expresamente como tempus commissi delicti la tesis del acto, no la del resultado. ${ }^{24}$ La imposibilidad de persecución sería en este caso, ya

\footnotetext{
${ }^{22}$ Diario de Sesiones del Congreso de los Diputados núm. 24, de 14 de octubre 1977.

${ }^{23}$ Así GARCÉS, “La Ley Española 46/1977”, cit. nota n 21.

24 Este sería el criterio de RODRÍGUEZ ARIAS, Miguel Angel, El caso de los niños perdidos del franquismo: crimen contra la humanidad, Valencia: Tirant lo Blanch, 2008, p. 2, quien sostiene que dada su
} 
TAMARIT, Josep. "Los límites de la justicia transicional penal:

la experiencia del caso español".

a estas alturas, de índole práctica, pues el tiempo transcurrido habrá hecho inviable la sumisión a juicio de los responsables intelectuales y materiales de los hechos.

En lo que atañe a los delitos que resultan efectivamente cubiertos por la Ley de amnistía de 15 de octubre de 1977, la aplicación de la misma, declarando la extinción de la responsabilidad penal, debería ser decidida caso por caso por el juez después de haber incoado un procedimiento penal en el cual debe precisarse: a) el hecho delictivo; b) la identidad del autor $\mathrm{u}$ otras personas indiciariamente responsables de los hechos delictivos y c) la motivación política. La propia Ley de amnistía prevé la forma en que debe ser aplicada, pese a que ha sido lamentablemente ignorada, al establecer en su art 9 que "sólo los jueces y Tribunales pueden decidir en cada caso la aplicación de la amnistía. Para ello deben adoptar, de acuerdo con la ley procesal y con carácter de urgencia, las decisiones pertinentes según esta Ley". ${ }^{25}$

Ante tales obstáculos, cabía plantear una doble estrategia respecto a los delitos no prescritos: o bien, lo cual resulta difícil, negar el carácter político del hecho para conseguir abrir un proceso penal que pueda llevar a la imposición de sanciones penales, o reconocer el carácter político con el objetivo de lograr una resolución, aunque sea de carácter interlocutorio y que ponga fin al proceso, en que queden fijados los hechos y de este modo pueda satisfacerse el derecho a la verdad y una satisfacción moral de las víctimas o sus descendientes, vía que se ha intentado en algún caso, con poco éxito.

\section{El caso de los niños perdidos y las adopciones ilegales}

Uno de los fenómenos más controvertidos ha sido el de los niños hijos de mujeres republicanas, que fueron separados de sus madres al ser éstas encarceladas y luego fueron entregados a familias que cumplían con las condiciones morales y políticas propias del régimen. ${ }^{26}$ Los hechos podrían ser calificados en el momento de su comisión como delito de suposición de parto, falsedad documental o incluso sustracción de menores, aunque difícilmente podría salvarse el escollo de la Ley de amnistía, ya que en todo caso se trataría de delitos políticos y la Ley de amnistía española, a diferencia de las leyes argentinas, tiene un alcance más amplio y radical, puesto que alcanza a todos los delitos de intencionalidad política, cualquiera que fuere su resultado. En estos casos el comportamiento estaba motivado por la ideología de las madres de los niños apropiados.

Distinto sería el caso de las adopciones ilegales, que en los últimos tiempos ha saltado a la luz pública y sobre el que la Fiscalía General del Estado ha anunciado una investigación y ha apuntado la posibilidad de ejercer acciones penales. Se trata de una serie de denuncias,

condición de delito permanente las detenciones ilegales seguidas de desaparición se seguirían cometiendo después de la Ley de amnistía. El argumento no puede compartirse, pues no se corresponde con el enunciado de la Ley de amnistía de 1977, según la cual a los efectos previstos en la ley los delitos se entenderán cometidos al momento de la realización de la acción. El resultado que alcanzamos es sin embargo el mismo, considerando que tales delitos no están amnistiados.

${ }^{25}$ Vid. en este sentido GARCÉS, “La Ley Española 46/1977”, cit. nota nº 21.

26 Una aproximación desde el punto de vista histórico puede verse en VINYES, Ricard, Irredentas. Las presas políticas y sus hijos en las cárceles franquistas, España: Ed. Planeta, 2010 ( $\left.1^{\mathrm{a}} \mathrm{ed} .2002\right)$. 
Polít. crim. Vol. 7, № 13 (Julio 2012), Art. 2, pp. 74 - 93.

[http://www.politicacriminal.cl/Vol_07/n_13/Vol7N13A2.pdf]

canalizadas a través de la asociación Anadir, ${ }^{27}$ relativas a conductas que se habrían ido produciendo durante todo el franquismo, incluso en los últimos años, consistentes en remover a niños de sus madres biológicas y entregarlos a otras familias. Los hechos podrían haber tenido una relativa proximidad con los que se han comentado anteriormente, dado que en muchos casos había un componente ideológico o moral si se trataba de niños que habían nacido en condiciones tenidas como inmorales y se trataba de proporcionarles una familia social y políticamente normalizada. Pero otros casos escapaban ya de esta lógica y obedecían a puros intereses económicos. Pese a ser un fenómeno que hay que vincular al menos con el denominado "franquismo sociológico", no nos encontraríamos ya ante delitos de intencionalidad política y por lo tanto no estarían cubiertos por la Ley de amnistía. Quedaría como único escollo la prescripción, lo que obligaría a examinar si nos encontramos ante delitos permanentes en los que se inicia el cómputo de la prescripción al cese de la situación ilícita. Así sería en los hechos que pudieran ser calificados como sustracción de menores, aunque la viabilidad de tal calificación sería muy dudosa. Los supuestos calificados como suposición de parto o sustitución de un niño por otro plantearían una mayor complejidad, si tenemos en cuenta que estas figuras, ubicadas en el CP 1944 en el título dedicado a los "delitos contra el estado civil", han sido consideradas doctrinalmente como delitos "de estado", que se diferenciarían de los delitos permanentes por el hecho de que el estado antijurídico creado por la acción del autor no es una situación que se prolongue en el tiempo bajo su control objetivo y subjetivo. Sin embargo, esta distinción no parece tan clara como frecuentemente había sido asumida y no puede olvidarse que una lectura de estos tipos delictivos conforme a los valores constitucionales les concede una nueva dimensión. Desde estos valores resulta procedente tener en cuenta como criterio decisivo el de la afectación al bien jurídico y la consideración de la víctima. En una perspectiva constitucional que permite superar el concepto predemocrático de "estado civil", el bien jurídico fundamentalmente protegido sería el derecho a la identidad personal, que goza de una protección fuerte en la medida que puede concebirse como emanación del derecho al libre desarrollo a la personalidad, definido como fundamento del orden político y la paz social (art 10-1 CE). En estos términos, la afectación al bien jurídico se prolonga durante todo el tiempo en que el sujeto se ha visto privado del conocimiento de su filiación, tiempo en el que ha sufrido la privación de las condiciones esenciales necesarias para la construcción de su propia identidad que el Estado debe garantizarle. Sería razonable entender en estos supuestos que el inicio del cómputo del plazo de prescripción no debería producirse como mínimo antes que la víctima no hubiera tenido la oportunidad de conocer el hecho. Ello da reales posibilidades de persecución penal de algunos de los supuestos de adopciones ilegales, pese a la insuficiencia y el carácter anacrónico de las tipologías delictivas aplicables al momento de la comisión de los hechos.

\section{Conclusión}

De lo examinado hasta el momento cabe concluir que las posibilidades de perseguir los delitos del franquismo se han ido desvaneciendo con el paso del tiempo, en parte por razones jurídicas y, sobretodo y definitivamente, por razones fácticas, dada la inviabilidad de someter a juicio a presuntos responsables que pudieren estar vivos y en condiciones de

${ }^{27}$ http://www.anadir.es, visitada el 8 de junio de 2011. 
TAMARIT, Josep. "Los límites de la justicia transicional penal:

la experiencia del caso español".

afrontar un juicio. El Estado democrático dejó pasar la oportunidad de iniciar un proceso penal en el que hubieran podido investigarse y en su caso ser condenados algunos de los responsables (no ya el dictador y otros dirigentes principales que habían muerto antes del fin de la dictadura) de los asesinatos masivos cometidos en los primeros años del régimen de Franco, delitos que hubieran podido ser calificados como asesinato y considerados no prescritos ni cubiertos por la ley de amnistía. Hoy cabría sustentar teóricamente la oportunidad de una persecución por los delitos de detención seguida de desaparición forzada, particularmente aquellos cometidos después de 1944, sólo en el hipotético caso que tras la investigación de los hechos no pudiera establecerse que la víctima hubiera sido asesinada (por no haberse identificado los restos), algo que provocaría la paradoja procesal de que la defensa pudiera estar interesada en probar el asesinato para favorecer la aplicación de la prescripción, lo cual en todo caso podría resultar aceptable para la acusación como medio pactado de establecer la verdad a través del proceso penal. En todo caso, nos movemos en el terreno de lo puramente hipotético, pues la hora de la justicia penal ya ha pasado. Una excepción sería el caso de las adopciones ilegales realizadas a lo largo de la dictadura que no quepa atribuir a una directa intencionalidad política, en cuyo caso puede haber incluso posibilidades reales de persecución de los hechos menos lejanos.

A todo ello cabe añadir la convicción, tantas veces señalada por los penalistas, de las limitaciones de la justicia penal para resolver los problemas sociales. Pese a la mitificación que desde diversos sectores sigue haciéndose del poder reparador de la justicia penal, debe constatarse una y otra vez que la misma difícilmente puede servir, en casos de macrovictimización como los que aquí se afrontan, a los objetivos de la pacificación y la restauración de las relaciones sociales. La aprobación en 2007 de la Ley de memoria histórica ha representado una ocasión perdida para crear una comisión de investigación oficial de carácter no jurisdiccional e independiente, formada por juristas y otros especialistas de reconocido prestigio (historiadores, médicos forenses...) con el encargo de realizar un relato de la victimización producida durante la guerra civil y el franquismo. Probablemente el tiempo transcurrido aconsejaría que el modelo no fuera el de las comisiones de la verdad con poderes para-judiciales de investigación, sino una comisión que partiera de los datos ya conocidos por la ciencia y tuviera ciertos poderes de investigación, como la dirección de la apertura de las fosas e identificación de los restos ${ }^{28}$. Se dirá en contrario que ello supondría que la política se arrogara el papel que corresponde al historiador o se advertirá del riesgo de querer imponer una verdad oficial, pero el historiador carece de ciertos poderes que pertenecen a la potestad del Estado y éste no puede abstenerse de su deber de promover el conocimiento de la verdad, lo cual no restringe la libertad de interpretación de los hechos históricos, ni excluye sino que puede facilitar la posibilidad de elaboración del relato personal, familiar o ideológico. Esta sería hoy una iniciativa necesaria para hacer frente al pasado y cumplir con las exigencias de verdad, justicia y reparación, aunque lamentablemente no parece que se den las condiciones políticas y sociales oportunas.

\footnotetext{
28 Me he ocupado con mayor detalle del estudio de las comisiones de la verdad en el plano internacional en "Comisiones de la verdad y justicia penal en contextos de transición”, Indret núm. 1 (2010), $\underline{\text { http://www.indret.com }}$
} 
Polit. crim. Vol. 7, No 13 (Julio 2012), Art. 2, pp. 74 - 93.

[http://www.politicacriminal.cl/Vol_07/n_13/Vol7N13A2.pdf]

\section{BIBLIOGRAFÍA}

AMBOS, Kai; MALARINO, Ezequiel; ELSNER, Gisela (Eds.), Justicia de transición: Informes de América Latina, Alemania, Italia y España, Berlin: Konrad-AdenauerStiftung, 2009, disponible en: http://www.kas.de/wf/doc/kas_15990-1522-430.pdf?090629220310

BASSIOUNI, M. Cherif, "Crimes against humanity: historical evolution and contemporary application”, Cambridge: Kluwer Law International, 2011.

CAPELLÀ ROIG, Margalida, "Los crímenes contra la humanidad en el caso Scilingo", REEI No 10 (2005).

DALY, Erin; SARKIN, Jeremy, Reconciliation in divided Societies: Finding Common Ground, Estados Unidos: University of Pennsylvania Press, 2006

ELSTER, Jon, Rendición de cuentas. El debate de la justicia transicional, Buenos Aires: Katz, 2004.

GARCÉS, J., “La Ley Española 46/1977 de Amnistía, más citada que leída, no tiene por objeto actos de naturaleza genocida y lesa humanidad", en: http://www.rebellion.org/docs/105976.pdf

GIL GIL, Alicia, La justicia de transición en España. De la amnistía a la memoria histórica, Barcelona: Atelier, 2009

HEYLEN, Ben; PARMENTIER, Stephan; WEITENKAMP, Elmar, "The Emergence of "Holistic Reconciliation": Lessons Learned from Victims and Offenders inside the South African Truth and Reconciliation Commission”, International Perspectives in Victimology, v. 5 (2010), p. 7.

HUYSE, Luc, "Justice after Transition: On the Choices Successor Elites Make in Dealing with the Past", en: KRITZ, Neil J. (Ed.), Transitional Justice: how emerging democracies reckon with former regimes, Washington D.C.: USIPP, 2004.

LASCURAIN, Juan Antonio, "Los límites de la amnistía", Doctrina penal No 28 (2011).

NINO, Carlos Santiago, "The duty to punish past abuses of human rights put into context: the case of Argentina", en: KRITZ, Neil J. (Ed.), Transitional Justice: how emerging democracies reckon with former regimes, Washington D.C.: USIPP, 2004.

OLLÈ SESÈ, Manuel, Justicia Universal para crímenes internacionales, Pamplona: La Ley, 2008.

PASTOR, Daniel, El poder penal internacional. Una aproximación jurídica crítica a los fundamentos del Estatuto de Roma. Barcelona: Atelier, 2006.

PIGRAU SOLÉ, Antoni, "La jurisdicción universal y su aplicación en España”, Barcelona: RxDH, 2009.

PRESTON, Paul, "El holocausto español”, Barcelona: Debate, 2010.

REYES MATE, Manuel, Justicia de las víctimas. Terrorismo, memoria, reconciliación. Madrid: Anthropos, 2009.

RODRÍGUEZ ARIAS, Miguel Angel, El caso de los niños perdidos del franquismo: crimen contra la humanidad, Valencia: Tirant lo Blanch, 2008.

TAMARIT SUMALLA, Josep, "Comisiones de la verdad y justicia penal en contextos de transición”, Indret núm. 1 (2010), http://www.indret.com 
TAMARIT, Josep. "Los límites de la justicia transicional penal:

la experiencia del caso español".

UPRIMNY YEPES, Rodrigo, en DE GAMBOA TAPIAS, Camila (Ed.), Justicia transicional: teoría y praxis, Bogotá: Universidad del Rosario, 2006.

VINYES, Ricard, Irredentas. Las presas políticas y sus hijos en las cárceles franquistas, España: Ed. Planeta, 2010 ( $1^{\text {a }}$ ed. 2002).

ZAPICO BARBEITO, Mónica, "Investigating the Crimes of the Franco Regime: Legal possibilities, Obligations of the Spanish State and Duties Towards the Victims", International Criminal Law Review, Vol. 10, № 2 (2010). 